\title{
Síntese das decisões do XIV Encontro do Fórum Nacional de Cursos de Geologia
}

\author{
Rualdo Menegat \\ Presidente do Fórum/ UFRGS \\ Celso Dal Ré Carneiro \\ Unicamp
}

Salvador, BA, 22 e 23 de setembro de 2014, por ocasião do $47^{\circ}$ Congresso Brasileiro de Geologia, promovido pela Sociedade Brasileira de Geologia

Citation: Menegat R., Carneiro C.D.R. 2014. Relato Final. XIV Encontro do Fórum Nacional de Cursos de Geologia. Salvador, BA. Terræ Didatica, 10(3):474-476. (Síntese das decisões, 22 e 23.09.2014). URL: http://www.ige.unicamp.br/terraedidatica/.

Os coordenadores e representantes de cursos de geologia, entidades e demais membros e participantes do XIV Encontro do Fórum Nacional de Cursos de Geologia, abaixo consignados, reuniram-se de 22 a 23 de setembro no Centro de Eventos da Bahia, na cidade de Salvador (BA), para avaliarem e discutirem a formação de geólogos nos cursos de graduação de geologia e engenharia geológica. Particularmente, discutiram-se de forma aprofundada os temas constantes da pauta. Destacamos as seguintes conclusões:

\section{Diretrizes Curriculares Nacionais dos Cursos de Geologia e Engenharia Geológica(DCNGeo)}

A recente aprovação pelo Conselho Nacional de Educação e subsequente homologação, em julho de 2014, pelo Exmo. Sr. Ministro de Educação, José Henrique Paim Fernandes, das Diretrizes Nacionais dos Cursos de Geologia e Engenharia Geológica colocou-se como uma conquista notável da comunidade de ensino de geologia de nossas universidades. Por um lado, atendeu a uma demanda histórica que fora encaminhada ao Conselho Nacional de Educação em 2001 (Expediente n ${ }^{\circ}$ 013245/2001-96), e posteriormente discutida em vários encontros do FNCG. No ano de 2012, realizamos uma reunião do FNCG na UnB, quando ratificamos a proposta de 2007, a qual foi encaminhada ao Conselheiro do CNE, Prof. Dr. Luiz Roberto Liza Curi, a quem agradecemos o empenho por ter sido o competente relator do processo. Gostaríamos, ainda, de destacar a notável colaboração do Prof. Dr. Valdecir Janasi, bastante diretor do IG/ USP, que esteve presente no ato de homologação havido no dia 01 de julho no MEC, em Brasília, e do Prof. Dr. Celso Dal Ré Carneiro, que soube tecer como ninguém os fios condutores desde a fundação deste Fórum Nacional até hoje.

Por outro lado, a aprovação das DCNGeo dá amparo legal para que a expansão de cursos de geologia esteja subordinada aos requisitos necessários para uma formação profissional de qualidade. Elas abrem um novo momento no ensino de geologia, pois nos obrigam a rever grades curriculares e procedimentos de ensino.

O XIV EFNCG reforça que as DCNGeo constituem importante instrumento para avançarmos na qualificação e atualização dos cursos de geologia bem como colocam-se como marco para balizar a implantação de novos cursos e promover adequadas condições de formação de recursos humanos. Em especial, o EFNCG destaca as seguintes orientações:

Duração do curso: A duração proposta para o curso, adotada no currículo a ser oferecido pela IES, é de cinco anos no mínimo e seis anos no máximo, com tempo recomendado de cinco anos, ou dez semes- 
tres, sendo que a carga horária mínima deve ser de 3.600 horas.

Atividades de ensino de campo: Deve ser planejada e incluída na programação dos cursos uma carga horária mínima de atividades de ensino de campo, que pode estar contida, ou não, na carga horária de diferentes disciplinas. A carga horária mínima é de $20 \%$ do total da carga mínima de 3.600 horas do curso, prevista no item 1.1 acima, ou seja, de 720 horas. O EFNCG avaliou a necessidade de que os cursos realizem todos os esforços para oferecer essa carga horária de campo. Dentre os instrumentos e medidas apontadas, sugerem-se as seguintes: (a) nos planos de ensino e súmulas das disciplinas, preferir a denominação "ensino de campo" ou "geologia de campo", em vez de "saída de campo", "excursão", "viagem de campo", "trabalho de campo" ou outras que não configurem que esse tipo de ensino é próprio da geologia, imprescindível para a formação do geólogo e que não pode ser realizado em outro lugar que não seja no campo. (b) incluir claramente no plano de ensino e súmulas das disciplinas a realização de atividades de "ensino de campo", especificando a devida carga horária. (c) os planos de ensino e súmulas constituem instrumentos legais e administrativos que ajudam a garantir os devidos orçamentos para viabilizar a execução das atividades de ensino de campo neles previstas.

Estágio supervisionado obrigatório: Considerou-se positiva a inclusão de estágio supervisionado obrigatório nas DCNGeo. Os cursos deverão prever tal atividade nos Projetos Pedagógicos de Cursos (PPC) como dispõe a Lei 11.788 de $25 / 09 / 2008$. Além disso, de acordo com o $\$ 3^{\circ}$ do Art. $1^{\circ}$ dessa Lei, entende-se que atividades de extensão, de monitoria e de iniciação científica na educação superior, desenvolvidas pelo estudante, podem ser equiparadas ao estágio obrigatório caso estejam devidamente previstas no projeto pedagógico do curso, especificando formas de operacionalização e de avaliação. A atividade ou disciplina de estágio tem como carga horária mínima sugerida de 120 horas a 160 horas, que pode ser concentrada em intervalo de 30 dias, no recesso de aulas escolares, ou distribuída ao longo do semestre.

\section{Segurança nas atividades de ensino de campo}

A comunidade de ensino vem apresentando crescente preocupação com a segurança e procedi- mentos legais relacionados às atividades de ensino de campo. Considera-se que essa preocupação contribui para que se discutam os procedimentos que possam tornar as práticas de ensino de campo cada vez mais profissionalizadas e amparadas administrativamente pelas IES. A segurança nas atividades de ensino de campo advém de um conjunto de medidas, que incluem preparação dos participantes por meio de seminários prévios, planejamento detalhado da logística das atividades, escolha de áreas apropriadas para o ensino de campo, duração das atividades e equipe de trabalho de campo adequadas ao número de participantes. Além disso, é importantíssimo o uso de instrumentos de avaliação de riscos e adoção de protocolos de segurança típicos que evidenciem a ciência dos riscos envolvidos bem como as medidas preventivas adotadas pelos participantes das atividades de campo.

\section{Sobre a designação "engenharia geológica"}

Com a implantação de novos cursos de geologia no país, é natural que as universidades procurem maneiras diferenciadas de ofertá-los. Contudo, considerou-se que a adoção de 'nomes diferentes' pode eventualmente implicar consequências mais profundas do que apenas tornar a oferta mais atrativa ao mercado educacional e profissional. No caso de designações como "engenharia geológica" há inevitáveis decorrências que podem conduzir para um perfil muito mais relacionado a uma engenharia do que propriamente ao da geologia, sendo que este último nome diferencia-se sobremaneira do primeiro devido à consistente base científica e epistemológica que o define como pertinente a uma ciência própria.

\section{Centros de referência de ensino de geologia}

Por ocasião do ato de homologação das DCNGeo, o professor Valdecir Janasi, em nome do Fórum Nacional de Cursos de Geologia, levou às mãos do Exmo. Sr. Ministro da Educação o projeto intitulado "Plano estratégico de qualificação e expansão da formação de recursos humanos em Geologia”. O projeto de expansão e qualificação da formação de recursos humanos em geologia por meio da implantação de Centros de Referência de Ensino de Geologia (CREGeo) foi reconhecido como deveras importante tanto para os cursos mais antigos quanto para os recém implantados. Considerou-se que a implantação de centros de 
ensino, especialmente os relacionados a ensino de campo, a exemplo do Centro de Geologia Eschwege (UFMG/MG), são necessários para proporcionar uma formação profissional com caráter mais nacional na medida em que que estudantes e professores de uma região podem realizar estágios de campo em outras localidades. Além disso, os centros de referência podem ajudar a alavancar a proposição de técnicas de ensino nas mais diversas áreas disciplinares, na estruturação de coleções de minerais, rochas e fósseis, laminotecas etc.

\section{Relações com a SBGeo}

O Encontro reitera proposições já anteriormente aprovadas de que o FNCG constitua-se também como Comissão de Ensino da Sociedade Brasileira de Geologia. Desse modo, as edições do Congresso Brasileiro de Geologia deveriam incluir em sua programação a realização do Encontro bem como inscrever automaticamente no congresso seus coordenadores.

\section{Próximo encontro e coordenação do biênio 2014-2016}

O próximo Encontro do Fórum Nacional de Cursos de Geologia deverá ser realizado na cidade do Rio de Janeiro no ano de 2015. Foram eleitos para a presidência do Fórum no próximo biênio o Prof. Dr. Francisco Oliveira da Silva, da UFRN, Natal, RN, e, para a secretaria, o Prof. Dr. Paulo de Tarso Ferro de Oliveira Fortes, da UFES, Alegre, ES.

\section{Indicação de membro honorário}

No encerramento do XIV Encontro do Fórum Nacional de Cursos de Geologia, foi aprovada por unanimidade a proposta de C.D.R. Carneiro, para que o Prof. Dr. Rualdo Menegat da UFRGS fosse nomeado Membro Honorário do FNCG, tendo em vista a relevante contribuição para as atividades do Fórum desde a sua criação.

\section{Lista de presenças no XIV Encontro do Fórum Nacional de Cursos de Geologia}

Por tipo de membro: a) coordenador de curso ordenado segundo a sigla do estado do curso, constante na $1^{\mathrm{a}}$ coluna; b) membro representante de entidade, c) membro honorário, e d) participantes sem direito a voto.

\section{ESTADO/ UNIVERSIDADE}

BA-UFBA

BA-UFOB

DF-UnB

ES-UFES

MG-UFOP

MG-UFMG

PE-UFPE

PR-UFPR

RJ-UFRJ

RJ-UERJ

RJ-UFRRJ

RN-UFRN

RS-UFRGS, Presidente do

FNCG

RS-UFRGS

RS-UNISINOS

RS-UNIPAMPA

SE-UFS

SP-USP

SP-UNESP

SP-UNIMONTE

\section{ENTIDADE}

ENEGE, presidente

FEBRAGEO

SBG, Vice-Presidente

Universidade Petrobras

\section{INSTITUIÇÃO}

SP-UNICAMP

\section{PARTICIPANTES}

[sem direito a voto]

A. Jorge Magalhães

Andre Rugenski

Carlos Eduardo de M. Barros

Caroline L. Cazarin

Haulton Mello da Silva

José Pedro Rebés Lima

Julio Carlos D. Sanglard

Marina Garcia de Magalhães

Quintino Mauro do Carmo

Renato V.S. Filho

Roberto Callari
MEMBRO

COORDENADOR E/OU REPRESENTANTE DE CURSO

Osmário Rezende Leite

Mary Anne Torres Garcia

Luciano Soares da Cunha

Paulo Fortes

Paulo de Tarso A. Castro

Alexandre Uhlein

Gorki Mariano

Rubens Jose Nadalin

Cícera Neysi de Almeida

Nely Palermo

Euzebio Jose Gil

Francisco Oliveira da Silva

Rualdo Menegat

Márcia Elisa Boscato Gomes

Francisco Manoel W. Tognoli

Marco Antônio F.Hansen

Aracy Sousa Senra

Valdecir Janasi

Jose Eduardo Zaine

Damara Cy Goya

MEMBRO REPRESENTANTE

DE ENTIDADE

Germano Alves Batista

João Cesar de Freitas Pinheiro

Egberto Pereira

Claudio Couto Reis

\section{MEMBRO} HONORÁRIO

Celso Dal Ré Carneiro

\section{INSTITUIÇÃO}

Universidade Petrobras

ANP

UFPR

Petrobras/CENPES

UFBA

UNIPAMPA

Universidade Petrobras

Datamine

CREA-RJ

Universidade Petrobras

Universidade Petrobras 